\title{
P. Masson, Les sept vies d'André Gide
}

\section{Elena Mazzoleni}

\section{(2) OpenEdition}

\section{Journals}

\section{Edizione digitale}

URL: http://journals.openedition.org/studifrancesi/10047

DOI: 10.4000/studifrancesi. 10047

ISSN: 2427-5856

\section{Editore}

Rosenberg \& Sellier

\section{Edizione cartacea}

Data di pubblicazione: 1 août 2017

Paginazione: 396

ISSN: 0039-2944

\section{Notizia bibliografica digitale}

Elena Mazzoleni, «P. Masson, Les sept vies d'André Gide», Studi Francesi [Online], 182 (LXI | II) | 2017, online dal 01 août 2017, consultato il 09 janvier 2021. URL: http://journals.openedition.org/ studifrancesi/10047 ; DOI: https://doi.org/10.4000/studifrancesi.10047

\section{Questo documento è stato generato automaticamente il 9 janvier 2021.}

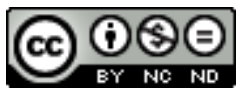

Studi Francesi è distribuita con Licenza Creative Commons Attribuzione - Non commerciale - Non opere derivate 4.0 Internazionale. 


\title{
P. Masson, Les sept vies d'André Gide
}

\author{
Elena Mazzoleni
}

\section{NOTIZIA}

PIERRE MASSON, Les sept vies d'André Gide, Paris, Classiques Garnier, 2016, 545 pp.

1 La complessità del percorso biografico delineato da Pierre Masson rispecchia perfettamente sia l'opera sia l'esistenza di André Gide. Il rapporto di quest'ultimo con i suoi scritti si è sempre manifestato in modo ambiguo: se, da un lato, egli vi ha trasfuso le sue esperienze personali nel tentativo di creare e ritrovare un'immagine di sé, dall'altro, la sua scrittura smentisce puntualmente qualsiasi ritratto definitivo del suo autore. Nei romanzi, nella corrispondenza e persino nel diario dello scrittore, la costruzione di sé passa, infatti, attraverso «une stratégie de séquençage de son être en postulations distinctes, contradictoires et complémentaires...» (p. 345).

2 Pierre Masson si propone di spiegare una trama d'aspirazioni, d'immagini e di ricordi apparentemente contraddittori, senza tuttavia tradirne i presupposti. Per restituire l'intreccio indissolubile tra vita e opera che caratterizza la scrittura gidiana, l'autore individua sette filoni, sette vite vissute da Gide. A ognuna corrisponde un capitolo della biografia, declinata secondo la vita del corpo, la vita con gli altri, la vita nomade, la vita di famiglia, la vita da scrittore, la vita morale ed infine quella spirituale. Attraverso questi sette profili, l'uno eco dell'altro, Masson riesce a dialogare con una figura stratificata e in continua evoluzione, restituita infine nella sua pienezza: «Il y a [...] dans ce composé de vie et de papier, plusieurs fils qui s'entremêlent, que nous allons suivre séparément, sachant bien que les divers visages qu'on obtiendra devraient être superposés» (pp. 14-15).

3 Tuttavia, l'obiettivo di Masson, esplicito sin dal prologo del saggio, non è tanto rendere conto dell'esistenza di Gide, quanto cogliere il senso dei suoi scritti alla luce del vissuto dell'uomo. Ciò che importa è mostrare i diversi volti di un'opera, la cui ricchezza è anche quella del suo autore. Un autore che non siamo chiamati a giudicare, bensì a comprendere. 
4 Questo saggio porta, infatti, uno sguardo critico inedito sull'opera gidiana; sviluppa un percorso analitico complesso, che giunge a mettere a fuoco un aspetto finora poco considerato dagli studi letterari: la profonda coerenza dei testi di Gide, costruiti sul riflesso del suo autore, colui che ha saputo far propria quella qualità rivendicata ora a un luogo, ora a un libro, di essere «à double fond» (p. 207). 